\title{
Tuberculosis in infancy
}

\section{Ben J Marais}

Address: Tygerberg Children's Hospital and Stellenbosch University Cape Town, South Africa

from Fifth Dominique Dormont International Conference. Mother-to-child transmitted viral diseases: from transmission to children care

Paris, France. 26-28 March 2009

Published: 22 July 2009

Retrovirology 2009, 6(Suppl I):L9 doi:I0.1 I86/1742-4690-6-SI-L9

This abstract is available from: http://www.retrovirology.com/content/6/SI/L9

(c) 2009 Marais; licensee BioMed Central Ltd.

Mother to child transmission of tuberculosis (TB) is not restricted to the first year of life, but it is a high risk period that illustrates all the important principles involved. The pregnant state increases a woman's vulnerability to develop TB and this is greatly amplified by co-existent HIV-related immune compromise. Mothers can transmit M. tuberculosis to their infants in three ways: 1) haematogenously via the placenta, 2) with aspiration and/or swallowing of infectious secretions during delivery and 3) post-partum via inhalation of small infectious particles. Haematogenous spread is most likely to occur if the mother develops primary infection with occult dissemination or frank disseminated disease during pregnancy. Infants represent the group at highest risk to develop severe forms of tuberculosis following primary infection, which justifies the provision of preventive chemotherapy following documented TB exposure and/or infection. The high risk experienced by HIV-exposed infants and the value/importance of infection control and various other strategies to reduce mortality and morbidity will be discussed. 